\title{
Urethral Cyst
}

National Cancer Institute

\section{Source}

National Cancer Institute. Urethral Cyst. NCI Thesaurus. Code C3971.

A cystic lesion located in the urethra. 